\title{
Clinical outcomes and costs of laparoscopic versus open appendectomy for appendicitis
}

\author{
Chang Sik Shin, Jae Il Kim*, Young Nam Roh, Pyong Wha Choi, Tae Gil Heo, Je Hoon Park, \\ Myung Soo Lee
}

Department of Surgery, Ilsan Paik Hospital, Inje University College of Medicine, 170, Juhwaro, Ilsanseogu, Goyangsi, Gyeonggido, Republic of Korea

\author{
Email address: \\ erythrokim@paik.ac.kr(J. Il Kim)
}

To cite this article:

Chang Sik Shin, Jae Il Kim, Young Nam Roh, Pyong Wha Choi, Tae Gil Heo, Je Hoon Park, Myung Soo Lee. Clinical Outcomes and Costs of Laparoscopic Versus Open Appendectomy for Appendicitis. Journal of Surgery. Vol. 1, No. 2, 2013, pp. 37-42.

doi: $10.11648 /$ j.js.20130102.17

\begin{abstract}
Purpose: The aim of this study was to compare clinical outcomes between open appendectomy (OA) and laparoscopic appendectomy (LA) for both uncomplicated appendicitis (UA) and complicated appendicitis (CA) and to help to choose the appropriate procedure for its management. Methods: The medical records of patients who underwent OA (OA group) or LA (LA group) for UA or CA between January 1, 2010 and December 31, 2011, were retrospectively reviewed. Results: For UA, time to a soft diet $(1.5 \pm 0.7$ in OA versus $1.4 \pm 0.7$ days in $L A, p=0.0010)$ and the length of hospital stay (3.9 \pm 1.5 in OA versus $3.3 \pm 1.4$ days in LA, $\mathrm{p}<0.0001)$ were significantly shorter in the LA group. The length of hospital stay for CA was significantly shorter in the LA group than in the OA group ( $7.5 \pm 3.8$ versus $4.9 \pm 2.8$ days, $\mathrm{p}=0.0012$ ). Complication rates were not significantly different between the LA and OA groups for both UA and CA. Conclusions: We conclude that for CA, clinical outcomes were better in the LA than in the OA group. For UA, there were no significant advantages of LA considering expensive hospital costs. The results of this study suggest that LA is the procedure of choice for patients with complicated appendicitis.
\end{abstract}

Keywords: Appendicitis, Appendectomy, Complication, Laparoscopy

\section{Introduction}

Acute appendicitis is the most common intra-abdominal condition requiring emergency surgery, although debate exists as to whether this is a true emergency [1]. Open appendectomy (OA) was the principal procedure for patients with acute appendicitis during the past century before the emergence of laparoscopic devices [2]. Generally, OA was performed through a relatively small skin incision and in a short operating time; therefore, patients experienced less pain and returned to work earlier as compared to those who underwent surgical procedures for other disease.

Since Semm [2] described the first laparoscopic appendectomy (LA) in 1983, laparoscopic procedures have been adopted in almost all surgical fields. Therefore, new laparoscopic instruments have been developed and laparoscopic surgical techniques have improved, and the ratio of patients undergoing LA rather than $\mathrm{OA}$ for appendicitis has increased. Moreover, recently introduced trans-umbilical single-port LA has become a popular procedure at some hospitals because it has a better cosmesis $[3,4]$.

It has generally been recognized that LA has many advantages in terms of cosmetic results, shorter hospital stay, regardless of age, obesity of patients and disease severity [5-7]. On the other hand, our previous study has reported that the hospital costs of LA were higher than those of OA [8]. However, controversies about the advantages and disadvantages of LA over OA for uncomplicated appendicitis (UA) and complicated appendicitis (CA) still exist. Reviews of the previous studies have been shown disagreements regarding the clinical outcomes of the 2 types of procedures except in terms of cosmetic results and hospital costs [8-15].

The aim of this study was to compare clinical outcomes and hospital costs between OA and LA for UA and CA, respectively, and to help to choose the appropriate procedure for management of patients with appendicitis. 


\section{Patients and Methods}

This study was designed as a retrospective, observational study at a single institution. The medical records of patients who underwent OA or LA for UA and CA between January 1, 2010 and December 31, 2011, were retrospectively reviewed.

\subsection{Patients}

In our hospital, all patients with suspicious appendicitis were checked by either computed tomography (CT) or ultrasonography, after which preoperative diagnoses were made. During the study period, a total of 951 patients were diagnosed with acute appendicitis. We excluded the following patients: those who underwent extended procedures, such as ileocecectomy, or who underwent other surgical procedures along with appendectomy, such as cholecystectomy or oophorectomy, pregnant women and those with severe other medical disease requiring intensive care, those with negative pathologic findings in the appendix. The remaining 866 patients were then divided into the LA and OA groups.

\subsection{Operative Procedures}

Eight surgeons carried out OA or LA in the cases during the study period. The operative procedure undertaken was chosen by each patient who received detailed descriptions about the procedures. The surgeons did not make the decisions. Informed consent included detailed explanations about the procedures, possible complications, and hospital costs. OA was carried out by the conventional method through $3-5 \mathrm{~cm}$ transverse skin incisions at the McBurney point. LA was performed by using 3 ports-1 umbilical port and 2 pubic ports or 1 umbilical port, 1 pubic port and 1 left lower abdominal port.

\subsection{Data Collection}

The collected clinical data included demographic characteristics, body mass index (BMI), initial body temperature, initial laboratory findings, operating time, postoperative laboratory findings, time to a soft diet, the amounts of analgesics used, pathologic results, complications, and the lengths of hospital stays. We analyzed preoperative, operative, and postoperative clinical data obtained from each group. Hospital costs consisted of the total costs covered by National Health Insurance (NHI) and charges. The data on the following items were analyzed: the total hospital costs, the total costs covered by NHI and copayment by patients.

\subsection{Statistical Analysis}

The data were analyzed using SAS enterprise ver. 4.3 statistical software (SAS Institute Inc, Cary, NC, USA). Demographic and clinical characteristics were expressed as means for continuous variables or proportions for categorical variables. The chi-square test was used to compare differences in categorical variables. Student's $t$ test or the Wilcoxon rank sum test was used to compare differences in continuous variables. The $p$ value of less than 0.05 was considered statistically significant.

\section{Results}

A total of 866 patients who underwent either OA or LA met the inclusion criteria. The number of patients in the LA group increased in 2011 when compared to 2010 for both UA and CA. However, there were no significant differences in the numbers of patients undergoing OA and those undergoing LA between 2010 and 2011 (Table 1). Of all patients, the number of patients with UA was $687(81.6 \%)$ and the number of patients with CA was 179 (18.4\%). LA was chosen by 125 patients $(18.2 \%)$ who had UA and by 20 patients $(11.2 \%)$ who had CA.

Table 1. Patients with appendicitis underwent surgical procedures between 2010 and 2011

\begin{tabular}{|c|c|c|c|c|c|c|c|}
\hline \multirow{2}{*}{ Year } & \multicolumn{3}{|c|}{ Uncomplicated appendicitis } & \multicolumn{3}{|c|}{ Complicated appendicitis } & \multirow{2}{*}{ Total } \\
\hline & OA & LA & Subtotal & OA & $\mathbf{L A}$ & Subtotal & \\
\hline 2010 & $\begin{array}{l}296 \\
(88.4 \%)\end{array}$ & $\begin{array}{l}39 \\
(11.6 \%)\end{array}$ & $\begin{array}{l}335 \\
(100 \%)\end{array}$ & $\begin{array}{l}75 \\
(91.5 \%)\end{array}$ & $\begin{array}{l}7 \\
(8.5 \%)\end{array}$ & $\begin{array}{l}82 \\
(100 \%)\end{array}$ & 417 \\
\hline 2011 & $\begin{array}{l}266 \\
(75.6 \%)\end{array}$ & $\begin{array}{l}86 \\
(24.4 \%)\end{array}$ & $\begin{array}{l}352 \\
(100 \%)\end{array}$ & $\begin{array}{l}84 \\
(86.6 \%)\end{array}$ & $\begin{array}{l}13 \\
(13.4 \%)\end{array}$ & $\begin{array}{l}97 \\
(100 \%)\end{array}$ & 449 \\
\hline Total & $\begin{array}{l}562 \\
(81.8 \%)\end{array}$ & $\begin{array}{l}125 \\
(18.2 \%)\end{array}$ & $\begin{array}{l}687 \\
(100 \%)\end{array}$ & $\begin{array}{l}159 \\
(88.8 \%)\end{array}$ & $\begin{array}{l}20 \\
(11.2 \%)\end{array}$ & $\begin{array}{l}179 \\
(100 \%)\end{array}$ & 866 \\
\hline
\end{tabular}

OA, open appendectomy; LA, laparoscopic appendectomy

Table 2. Demographic and preoperative clinical characteristics of patients with uncomplicated appendicitis or complicated appendicitis

\begin{tabular}{|c|c|c|c|c|c|c|}
\hline \multirow{2}{*}{ Variable } & \multicolumn{2}{|c|}{ Uncomplicated appendicitis } & \multirow{2}{*}{$p$-value } & \multicolumn{2}{|c|}{ Complicated appendicitis } & \multirow{2}{*}{$p$-value } \\
\hline & $\mathrm{OA}(\mathrm{n}=562)$ & $\mathrm{LA}(\mathrm{n}=125)$ & & $\mathrm{OA}(\mathrm{n}=159)$ & $\mathrm{LA}(\mathrm{n}=20)$ & \\
\hline Sex (Males : Females) & $340: 222$ & $50: 75$ & $<0.0001$ & $96: 63$ & $10: 10$ & 0.3734 \\
\hline
\end{tabular}




\begin{tabular}{lllllll}
\hline Age (year) & $31.1 \pm 17.2$ & $29.1 \pm 12.9$ & 0.1414 & $34.2 \pm 21.2$ & $28.9 \pm 10.0$ & 0.0646 \\
Body Mass Index $\left(\mathrm{kg} / \mathrm{m}^{2}\right)$ & $21.9 \pm 3.5$ & $22.2 \pm 3.5$ & 0.3857 & $21.9 \pm 3.9$ & $22.2 \pm 3.6$ & 0.7238 \\
Body temperature $\left({ }^{\circ} \mathrm{C}\right)$ & $37.0 \pm 0.6$ & $37.0 \pm 0.5$ & 0.9118 & $37.6 \pm 0.9$ & $37.3 \pm 0.8$ & 0.2886 \\
Initial WBC $\left(\mathrm{x} 10^{3} / \mathrm{mm}^{3}\right)$ & $13.08 \pm 4.24$ & $13.04 \pm 3.88$ & 0.9344 & $14.64 \pm 4.51$ & $14.98 \pm 3.31$ & 0.7448 \\
\hline
\end{tabular}

Values are presented as numbers, means and standard deviation.

OA, open appendectomy; LA, laparoscopic appendectomy; WBC, white blood cell

Table 2 shows the demographic data and preoperative clinical data of both patients with UA and those with CA. Patients undergoing LA were predominantly female for UA and there were significant differences in sex between the OA and LA groups (39.5\% versus $60.0 \% p<0.0001)$. There were no significant differences in age, BMI, initial body temperature, and white blood cell (WBC) count between the OA and LA groups. On the other hand, for CA, there were no significant differences in any demographic and preoperative clinical data including sex ratio between the OA and LA groups.

\subsection{Clinical Outcomes}

Table 3. Operative and postoperative clinical characteristics of patients with uncomplicated appendicitis or complicated appendicitis

\begin{tabular}{|c|c|c|c|c|c|c|}
\hline \multirow{2}{*}{ Variable } & \multicolumn{2}{|c|}{ Uncomplicated appendicitis } & \multirow{2}{*}{$p$-value } & \multicolumn{2}{|c|}{ Complicated appendicitis } & \multirow{2}{*}{$p$-value } \\
\hline & $\mathrm{OA}(\mathrm{n}=562)$ & $\operatorname{LA}(n=125)$ & & OA $(n=159)$ & $\mathrm{LA}(\mathrm{n}=20)$ & \\
\hline Operating time (minute) & $45.3 \pm 17.9$ & $65.6 \pm 20.6$ & $<0.0001^{*}$ & $60.7 \pm 22.0$ & $70.2 \pm 19.4$ & $0.0693^{*}$ \\
\hline Combined drainage, case $(\%)$ & $38(6.8 \%)$ & $5(4.0 \%)$ & $0.3103^{\ddagger}$ & $111(69.8 \%)$ & $5(25.0 \%)$ & $<0.0001^{\ddagger}$ \\
\hline Appendicoliths, case (\%) & $218(38.8 \%)$ & $41(32.8 \%)$ & $0.2223^{\ddagger}$ & $85(53.5 \%)$ & $13(65.0 \%)$ & $0.3529^{*}$ \\
\hline $\begin{array}{l}\text { WBC, postoperative first day } \\
\left(\mathrm{x} 10^{3} / \mathrm{mm}^{3}\right)\end{array}$ & $9.61 \pm 3.09$ & $9.27 \pm 2.62$ & $0.2121^{*}$ & $11.78 \pm 4.55$ & $11.97 \pm 3.84$ & $0.8627^{*}$ \\
\hline Time to soft diet (day) & $1.5 \pm 0.7$ & $1.4 \pm 0.7$ & $0.0010^{\dagger}$ & $2.6 \pm 1.3$ & $2.1 \pm 0.9$ & $0.1371^{\dagger}$ \\
\hline Postoperative hospital stay (day) & $3.9 \pm 1.5$ & $3.3 \pm 1.4$ & $<0.0001^{\dagger}$ & $7.5 \pm 3.8$ & $4.9 \pm 2.8$ & $0.0012^{\dagger}$ \\
\hline Amount of analgesics & $1.2 \pm 1.2$ & $1.1 \pm 1.3$ & $0.1448^{\dagger}$ & $3.0 \pm 4.1$ & $2.3 \pm 2.5$ & $0.4902^{\dagger}$ \\
\hline Complication, case $(\%)$ & $13(2.3 \%)$ & $5(4.0 \%)$ & $0.3472^{\ddagger}$ & $22(13.8 \%)$ & $2(10.0 \%)$ & $0.7470^{\ddagger}$ \\
\hline
\end{tabular}

* Statistic result by using Student t-test

$\dagger$ Statistic result by using the Wilcoxon rank sum test

\$ Statistic result by using the $\chi 2$ test

Table 4. Operation-related complications

\begin{tabular}{|c|c|c|c|c|c|c|}
\hline \multirow{2}{*}{ Complication } & \multicolumn{2}{|c|}{ Uncomplicated appendicitis } & \multirow{2}{*}{$p$-value } & \multicolumn{2}{|c|}{ Complicated appendicitis } & \multirow{2}{*}{$p$-value } \\
\hline & $\mathrm{OA}(\mathrm{n}=562)$ & $\mathrm{LA}(\mathrm{n}=125)$ & & OA $(n=159)$ & $\mathrm{LA}(\mathrm{n}=20)$ & \\
\hline Wound infection & $8(1.4 \%)$ & $3(2.4 \%)$ & 0.4302 & $14(8.8 \%)$ & $1(5.0 \%)$ & 1.0000 \\
\hline Intra-abdominal abscess & $2(0.4 \%)$ & $1(0.8 \%)$ & 0.4531 & $5(3.1 \%)$ & $1(5.0 \%)$ & 0.5141 \\
\hline Intestinal obstruction & $3(0.5 \%)$ & $1(0.8 \%)$ & 0.5530 & $3(1.9 \%)$ & 0 & 1.0000 \\
\hline Total & $13(2.3 \%)$ & $5(4.0 \%)$ & 0.3472 & $22(13.8 \%)$ & $2(10.0 \%)$ & 0.7470 \\
\hline
\end{tabular}

Statistic result by using the $\chi^{2}$ test

Table 5. Analysis of hospital costs of patients with uncomplicated appendicitis or complicated appendicitis

\begin{tabular}{|c|c|c|c|c|c|c|}
\hline \multirow{2}{*}{ Variable } & \multicolumn{2}{|c|}{ Uncomplicated appendicitis } & \multirow{2}{*}{$p$-value } & \multicolumn{2}{|c|}{ Complicated appendicitis } & \multirow{2}{*}{$p$-value } \\
\hline & $\mathrm{OA}$ & LA & & $\mathrm{OA}$ & LA & \\
\hline Total hospital costs & $\begin{array}{c}2,267,101 \pm 474,60 \\
1\end{array}$ & $\begin{array}{c}3,030,201 \pm 545,74 \\
9\end{array}$ & $<0.0001$ & $3,036,100 \pm 925,010$ & $\begin{array}{c}3,459,952 \pm 813,58 \\
0\end{array}$ & 0.0521 \\
\hline $\begin{array}{c}\text { Total costs covered by } \\
\text { NHI }\end{array}$ & $\begin{array}{c}1,207,615 \pm 224,00 \\
1\end{array}$ & $\begin{array}{c}1,675,483 \pm 268,71 \\
9\end{array}$ & $<0.0001$ & $1,656,790 \pm 508,385$ & $\begin{array}{c}1,892,392 \pm 401,33 \\
0\end{array}$ & 0.0477 \\
\hline Copayment by patients & $416,372 \pm 91,344$ & $517,520 \pm 117,381$ & $<0.0001$ & $539,458 \pm 176,086$ & $602,936 \pm 143,402$ & 0.1235 \\
\hline
\end{tabular}

Values are presented as KRW (Korean won, Korean monetary unit)

$1 \mathrm{USD}=1,108 \mathrm{KRW}$

NHI, National Health Insurance

Table 3 shows the results of comparisons of operative and postoperative clinical data and complication rates between the OA and LA groups for both UA and CA. Operating time for UA was significantly longer in the LA group than in the OA group $(65.6 \pm 20.6$ minutes versus
$45.3 \pm 17.9$ minutes, $p<0.0001)$. However, time to a soft diet and the length of postoperative hospital stay were significantly shorter in the LA group than in the OA group ( $1.4 \pm 0.7$ versus $1.5 \pm 0.7, p=0.001 ; 3.3 \pm 1.4$ versus $3.9 \pm 1.5$, $p<0.0001)$. The other results, including complication rates 
showed no statistical differences between the two groups. Operating time for CA was slightly longer in the LA group than in the OA group, but the difference was not statistically different $(70.2 \pm 19.4$ versus $60.7 \pm 22.0$ minutes, $p=0.0693$ ). Unlike for UA, the percentage of patients who underwent external drainage procedures was significantly higher in the OA group than in the LA group (69.8\% versus $25.0 \%, p<0.0001)$. Time to a soft diet was not significantly different between the two groups. Like for UA, the length of postoperative hospital stay was significantly shorter in the LA group than in the OA group $(4.9 \pm 2.8$ versus $7.5 \pm 3.8$ days, $p=0.0012$ ). There were no significant differences in frequency of appendicoliths, WBC counts on the first postoperative day, amount of analgesics, and complication rates between the two groups.

Among postoperative complications, operation-related complications for CA were more frequent than those for UA regardless of the choice of operative procedure (Table 4). Wound infections were the most common complication in all patients, especially those in the OA group for CA. In the LA group, all wound infections for both UA and OA developed at the umbilical port sites. Intra-abdominal abscesses occurred in 9 patients in each group, who were treated with intravenous antibiotics or percutaneous drainage without operative management. Intestinal obstruction occurred in 7 patients in each group, 2 of who needed re-exploration. One patient (male, 8 years old) underwent adhesiolysis after OA for CA on the eighteenth postoperative day due to mechanical obstruction by an adhesive band and underwent small bowel resection due to intestinal strangulation 10 months after appendectomy. The other patient (female, 27 years old) received adhesiolysis after LA for UA on the seventh postoperative day due to adhesion at the umbilical port site.

\subsection{Hospital Costs}

Analysis of hospital costs presented different results for both UA and CA (Table 5). For UA, the total hospital costs, total costs covered by National Health Insurance (NHI) and copayment by the patients were higher in the LA group than in the OA group $(3,030,201 \pm 545,749$ versus $2,267,101 \pm 474,601, p<0.0001 ; 1,675,483 \pm 268,719$ versus $1,207,615 \pm 224,001, \quad p<0.0001 ; 517,520 \pm 117,381$ versus $416,372 \pm 91,344, p<0.0001$; respectively). For CA, the total cost covered by NHI was higher in the LA group than in the OA group $(1,892,392 \pm 401,330$ versus $1,656,790 \pm 508,385$, $p=0.0477$, but the others were not statistically different.

\section{Discussion}

In 1886, Reginald Fitz of Boston correctly identified the appendix as the primary cause of right lower quadrant inflammation and recommended its early surgical treatment [16]. Since then, OA became the principal treatment method for appendicitis before the emergence of laparoscopic devices. Despite some differences among countries, LA has been popular because of several advantages over OA [10-12].

Despite the several clinical benefits of LA, such as cosmetic appearance and excellent outcomes, regardless of disease severity or patients' age [5-8, 10-12], the optimal surgical approach for patients with appendicitis is still debated. In addition, it is hard to unequivocally say that LA is better because of the higher hospital costs for LA seen in some studies $[8,12,13,15]$.

If patients with acute right lower quadrant pain visited our outpatient clinic or emergency room, we evaluated them through comprehensive history taking, physical examination and laboratory tests. If appendicitis was suspected, radiologic studies, such as abdominal sonography or computed tomography (CT) were performed on all patients. Radiologic evaluation helped surgeons to confirm the diagnosis and to recognize the location of the appendix and other intra-abdominal conditions requiring additional procedures. When the diagnosis was made, the operative procedure was chosen by the patient who received detailed descriptions of the procedures.

For both UA and CA, the number of patients who underwent LA was lower than the number of patients who underwent $\mathrm{OA}$. The percentage of CA patients to the total patients was only $18.4 \%$, and LA for CA was chosen only by 20 patients $(11.2 \%)$. Patients may have distorted understandings of the advantages of LA or may have understood that the hospital costs were higher in the LA group than in the OA group. However, the percentage of patients in the LA group to those in the OA group gradually increased from $11.0 \%$ in 2010 to $22.0 \%$ in 2011 , and this trend was seen in both UA and CA, although only $11.2 \%$ of CA patients underwent LA.

In comparisons of demographic and preoperative clinical data, females with in UA predominantly chose LA, while there were no significant differences in the sex ratio between CA patients who underwent LA and those who underwent OA. This result implies that $\mathrm{CA}$ patients receiving explanations about the relatively higher rate of postoperative intra-abdominal abscess formation after surgery tended to choose OA. However, we observed that there were no significant differences in postoperative intraabdominal abscess formation between the OA and LA groups for $\mathrm{CA}$, although the number of patients undergoing LA was very low, similar to the results reported in other recent studies $[9,11,17]$.

In comparisons of clinical outcomes, in both UA and CA patients, the length of postoperative hospital stay of LA was significantly shorter in the LA group than in the OA group. This result is similar to those reported by most of the previous studies [8, 10-12]. For UA, time to a soft diet was shorter in the LA group than in the OA group, while for CA it was not significantly different between the two groups. This may be because resumption of a soft diet for CA was delayed until inflammation or edematous changes in the intestine improved. For both UA and CA, the amounts of analgesics used were not significantly different between the 
OA and LA groups. And this results was inconsistent with results reported by some meta-analyses [18, 19]. The reason for this may be explained that relatively small incisions and minimal invasiveness to tissue in the $\mathrm{OA}$ group as well as in the LA group.

For CA, the number of patients who underwent drainage procedures during appendectomy was significantly lower in the LA group than in the OA group, while the same was not seen for UA. Wide field of view and effective aspiration of intra-abdominal exudative fluid or pus with laparoscopic suction devices may have led to the lower rates of external drainage. Therefore, it is assumed that the occurrence rate of intra-abdominal abscesses after LA was similar to or less than that after OA, whereas previous studies have shown that abscesses are more frequent after LA than after OA [19, 20].

In this study, we observed significantly low rate of intestinal obstruction in LA and OA groups. In the LA group, only 1 patient developed intestinal obstruction on the third postoperative day and underwent laparotomy again on the seventh postoperative day. This observation was probably due to adhesion of the small intestine and peritoneum at the umbilical trocar site or mistakes during closure with suture materials. When surgeons close the wound of a trocar insertion site, special attention should be paid not to enclose the intestine. All other patients with intestinal obstruction occurred after OA. Theoretically, LA reduces interference to the microenvironment and damage to the intestinal serous membrane and thus decreases the frequency of adherence between the intestines [18].

Previous studies have demonstrated that operating time is longer in the LA group than in the OA group [18-21]. In our study, operating time for LA was similarly longer for both UA and CA, while that for OA was shorter only for UA. This implies that operating times for LA and OA may be different among UA patients. It is thought that operating time is generally longer in the LA group than in the OA group because LA requires waiting time for adequate pneumoperitoneum, trocar insertion, and the arrangement and exchange of different laparoscopic devices. This is a drawback of LA despite its good outcomes.

Although hospital costs are difficult to compare between different countries because of differences in health care and health insurance systems, LA has gradually been shown to be more expensive than $\mathrm{OA}$ in the literature $[8,13,20]$. In Korea, total hospital costs consist of the total amount of health benefits and charge for non-covered items, for example, non-covered bed charges. NHI supports $80 \%$ of the total hospital costs except for non-covered items, thus patients only pay $20 \%$ of the total costs plus the noncovered items. Generally, health care service costs are less expensive in Korea than in other developed countries. Therefore, hospital costs for LA are naturally more expensive than those for OA because of the additional charges for disposable instruments unless other costs are reduced. Our study demonstrated that for UA, LA was more expensive than $\mathrm{OA}$ while for $\mathrm{CA}$, there were no significant differences in hospital costs other than total costs covered by NHI between the OA and LA groups. The reason for these results may be that shortening of hospital stay in the LA group was more effective for CA (2.6 days) than that for UA (0.6 days). These results indicate that LA for CA is cost effective and leads to better outcomes.

\section{Conclusions}

Although this is a retrospective observational study and the sample size of the LA group for CA was relatively small, we conclude that for CA, clinical outcomes were better in the LA group than in the OA group, without any increase in complication rates. For UA, there were no significant advantages of LA considering expensive hospital costs, although shorter time to soft diet and postoperative hospital stays in LA group. The results of this study suggest that LA is the procedure of choice for patients with complicated appendicitis. Operative procedure should be chosen by patients with uncomplicated appendicitis whether they undergo OA or LA.

\section{Disclosure}

This work was supported by the 2011 Inje University research grant. All authors confirmed no conflict of interest relevant to this article.

\section{References}

[1] Hansson J, Korner U, Ludwigs K, Johnsson E, Jonsson C, Lundholm K. Antibiotics as First-line Therapy for Acute Appendicitis: Evidence for a Change in Clinical Practice. World J Surg. 2012;36:2028-2036

[2] Semm K. Endoscopic appendectomy. Endoscopy. 1983;15:59-64

[3] Park J, Kwak H, Kim SG, Lee S. Single-port laparoscopic appendectomy: comparison with conventional laparoscopic appendectomy. J Laparoendosc Adv Surg Tech A. 2012;22:142-145

[4] Kim HJ, Lee JI, Lee YS, Lee IK, Park JH, Lee SK, Kang WK, Cho HM, You YK, Oh ST. Single-port transumbilical laparoscopic appendectomy: 43 consecutive cases. Surg Endosc. 2010;24:2765-2769

[5] Southgate E, Vousden N, Karthikesalingam A, Markar SR, Black S, Zaidi A. Laparoscopic vs open appendectomy in older patients. Arch Surg. 2012;147:557-562

[6] Masoomi H, Mills S, Dolich MO, Ketana N, Carmichael JC, Nguyen NT, Stamos MJ. Does laparoscopic appendectomy impart an advantage over open appendectomy in elderly patients? World J Surg. 2012;36:1534-1539

[7] Mason RJ, Moazzez A, Moroney JR, Katkhouda N. Laparoscopic vs open appendectomy in obese patients: outcomes using the American College of Surgeons National Surgical Quality Improvement Program database. J Am Coll Surg. 2012;215:88-99; discussion 99-100 
[8] Lee HJ, Park YH, Kim JI, Choi PW, Park JH, Heo TG, Lee MS, Kim CN, Chang SH. Comparison of clinical outcomes and hospital cost between open appendectomy and laparoscopic appendectomy. J Korean Surg Soc. $2011 ; 81: 321-325$

[9] Suh YJ, Jeong SY, Park KJ, Park JG, Kang SB, Kim DW, Oh HK, Shin R, Kim JS. Comparison of surgical-site infection between open and laparoscopic appendectomy. J Korean Surg Soc. 2012;82:35-39

[10] Saia M, Buja A, Baldovin T, Callegaro G, Sandona P, Mantoan D, Baldo V. Trend, variability, and outcome of open vs. laparoscopic appendectomy based on a large administrative database. Surg Endosc. 2012;26:2353-2359

[11] Masoomi H, Mills S, Dolich MO, Ketana N, Carmichael JC, Nguyen NT, Stamos MJ. Comparison of outcomes of laparoscopic versus open appendectomy in children: data from the Nationwide Inpatient Sample (NIS), 2006-2008. World J Surg. 2012;36:573-578

[12] Tiwari MM, Reynoso JF, Tsang AW, Oleynikov D. Comparison of outcomes of laparoscopic and open appendectomy in management of uncomplicated and complicated appendicitis. Ann Surg. 2011;254:927-932

[13] McGrath B, Buckius MT, Grim R, Bell T, Ahuja V. Economics of appendicitis: cost trend analysis of laparoscopic versus open appendectomy from 1998 to 2008 . J Surg Res. 2011;171:e161-168

[14] Markar SR, Blackburn S, Cobb R, Karthikesalingam A, Evans J, Kinross J, Faiz O. Laparoscopic Versus Open Appendectomy for Complicated and Uncomplicated Appendicitis in Children. J Gastrointest Surg. 2012;16:1993-2004
[15] Sporn E, Petroski GF, Mancini GJ, Astudillo JA, Miedema BW, Thaler K. Laparoscopic appendectomy--is it worth the cost? Trend analysis in the US from 2000 to 2005. J Am Coll Surg. 2009;208:179-185 e172

[16] Maa J, Kirkwood KS. The Appendix. In: Townsend CM, Sabiston DC (eds) Sabiston textbook of surgery : the biological basis of modern surgical practice, Saunders Elsevier, Philadelphia, 2008 pp 917-973

[17] Nataraja RM, Teague WJ, Galea J, Moore L, Haddad MJ, Tsang T, Khurana S, Clarke SA. Comparison of intraabdominal abscess formation after laparoscopic and open appendicectomies in children. J Pediatr Surg. $2012 ; 47: 317-321$

[18] Wei B, Qi CL, Chen TF, Zheng ZH, Huang JL, Hu BG, Wei HB. Laparoscopic versus open appendectomy for acute appendicitis: a metaanalysis. Surg Endosc. 2011;25:11991208

[19] Li X, Zhang J, Sang L, Zhang W, Chu Z, Liu Y. Laparoscopic versus conventional appendectomy--a metaanalysis of randomized controlled trials. BMC Gastroenterol. 2010;10:129

[20] Sauerland S, Jaschinski T, Neugebauer EA. Laparoscopic versus open surgery for suspected appendicitis. Cochrane Database Syst Rev. 2010:CD001546

[21] Liu Z, Zhang P, Ma Y, Chen H, Zhou Y, Zhang M, Chu Z, Qin H. Laparoscopy or not: a meta-analysis of the surgical effects of laparoscopic versus open appendicectomy. Surg Laparosc Endosc Percutan Tech. 2010;20:362-370 